\section{ON A CASE OF GASTRIC HAMORRHAGE.} BY HETRY R. OSWALD, M.D. EDIN.

MRs. R_- aged twenty-four, had not felt well for several months (one of her most troublesome symptoms beiug pain in the epigastrium and back), when, on the evening of Nov. 13th, 1880, she fainted. The following is a recurd of the more pro aninent symptoms from the day I first visited the patient :-

Nov. 14th : At 4 A.Mr. vomited a large quantity of dark blood, and at 8 A.M. about a teacupful of bright-coloured blood. More blood of a bright hue was brought up at 6 P.M. Shortly afterwards the bowels were moved, the stool containing dark blood. Pain in the epigastrium. Mineral acid was prescribed. Ordered ice to be sucked, room to be kept cool, rest in horizontal position. -15th: Blood, fluid aud coagulated, vomited at 2 A.M. Gallic acid prescribed.16th: At 1 A.M. a small amount of bright blood, and at 7 A.M. a large amount of darker blood, fluid and cuagulated, was vomited. Copious bloody motion during the day. Patient exsinguine, skin cold, pulse small and feeble. Till now she had taken ice and gallic acid. At this period, on account of the uryency of the case, I deemed it advisable to try ergot. An enema of half an ounce of the solution of the extract of ergot, in water, was used about midday. 17th : Patient vomited several times, but passed no more blood since the injection, either by mouth or rectum. A small enema of beef-tea and brandy given.-18th : Headache and nausea complained of, but no more sickness. A very slight menstrual flow began. Another beef-tea enema administered, and a little slop-food allowed. Bowels unmoved since enema of ergot. Pills of bismuth prescribed. - 19th : No sickness; no bleeding; appetite returning. Bismuth continued.-20th : Headache; tongue coated and clammy. Food of a semi-liquid form fairly well taken. -2lst: Headache and coated tongue remain. Has been ordered brandy each day since the 17th. -22 nd Stili very anæmic. Appetite fair. Partook of whiting to-day, bread, and an egg. Brandy contiuued. The howels not having been opened since the $16 \mathrm{th}$, an enema of gruel was admiuistered at 130 P. M. without result. Repeated at 10.30 P. M., and followed by a dark motion. No bleeding. Bismuth still prescribed.-23rd: Felt sick, but did not vomit. Appearance of patient still bloodless. Slept little. Ate fish, bread, and butter. Bowel $\$$ moved without ald. 24th : Partook of some mutton. Late in the evening an injection was given, followed by copious dark motion.25th : No movement of buwels.-27th : Symptoans gradually improved. Constipation remained obstinate, and required enemata at various dates. Ammonio-citrate of iron com menced on this day, and was taken till the recove; $y$ of the patient. In three weeks from the first day of attack she was able to leave her bed, and in six to desceud frum her bedroom. Nausea remrned occasionally, but was amenable to treatment by bismuth. In January, 1881, the patient went to the seaside. No hæmorrhage had orcurred since the 16th of November previous. In July, 1881, during my absence from town, Mrs. R- suffered fro.n another al tack similar to that just detailed, but much less urgent. It was happily soon subdued by astringents. At the present date Mrs. $\dot{R}-$ is in fair health. She always complains, however, of constipation, and of a feeliug of constriction around the abdomen ahout the level of the umbilicus

Remarlis. - There can be lictle doubt this was a serious case of gastric ulcer. I have been indui:ed to relate the symptoms, however, to illu strate the specific action of ergot rather than to give an exhaustive clinical account of that malady. Iu a compar sin of the effects of bellailonnt aud ergot on involuntary muscular fibre, Dr. Browu-Séquard observes that the lattor drus acts chiefly on the uterus and the vessels of the spinal cord. I presume he spraks of itphysiological astion; f r, in the present iustan the thera. peutic effect, of ergot on the stomath was sufficiently distinct and notable. So much blond had been lost-its colour at times leading one to suspect it was partly arterial-that in forty-eight hours from the heginning of the attack the patient's friends despaired of ber recovery. No syucope took place after the vomiting commenced. Therefore, the action of the ergot enema was not thus adventitiously helped, and from the date of its administration not a drop more blord escaped either by mouth or rectum. The dark fiecd evacuation: mentioned were owing to bismuth. In such a case, then, how does ergot act? Not to enter into its rt puted primary action on the sympathetic system of uerves, I cunclude that its effects are developed, through involuu tary muscular fibre, in three directions.

1. Through the arteries. There is reason to bulitre the capillaries of the stomach contain in their coat a larger supply of non-voluntary muscular fibre than most arterial vessels. Consequently the contraction of these, after absorption of ergot by the system, is firm, and the flow of bluod along them relatively inconsiderable or possibly nil. The chance of its escape at an ulcerated surface is thus materially diminished.

2. Through the veins. From the same cause the venous capillaries are similarly reduced in calibre, but also from their natural tendency to adapt their size to the supply of blood corning from the arteries. By this means the danger, if any, of regurgitation is obviated, aud the ulcer lett less disturbed.

3. Through the muscular coat of the stomach, which con. sists of three sets of fibres, longicudinal, circular, and oblique, of the involuntary kind, the influence of ergot is most probably again asserted. By contraction of these tibres the stomach, it may be inferred, is thrown into folds, compression of the bloodvessels passing through the muscular coat being one result, and perhaps some adaptation of the ulcerated parts to each other another. In this manner the muscles of the stomtch assist the capillaries, and may also promote healing of an ulcer by approximating its edges.

In the treatment of gastric ulcer it is of extreme import. ance, especially in case of hæmatemesis, to feed the parient with nutrient enemata and to avoid, as far as possible, the ingestion of auy articles to the stomach. For not only does the presence of ford or drugs disturb the denuded part, but by exciting the function of digestion stimulates a flow of blood to it.

In conclusion I wish to observe that, whichever may be the organs most affected by ergot physiologically, it exercises in disease a distinct control over any involuntary muscle in which a bieach of continuity exists leading to hæmorrbage.

Camberwell New-road, S.E.

\section{REMARKABLE CASE OF INJURY TO THE} LEG FROM A FALL.

\section{BY DUNCAN ALISTAIR MAC GREGOR, II.B.ED.}

THE following case is perhaps of sufficient interest to be put on record in THE LANCET.

Oa the evening of June 15th, 1881, I was havtily sun! moned to see a lad, aged fifteen years, who had iujured his leg by falling off an outhouse. I was told that the limb was very badly cut, and that a "long worm-like thing" was hanging out of the wound. On arrival, I found my putient sitring on a chair, and at first sight it seemed as if there was l-ttle the matter with him, as he was laughing heartily apparent,y amused at the serious view his riatives were taking of the accident.

Upon examining the right leg, I found in frout a derp lonsitudinal jagg-d wound, about two iuches in length, almo $t$ inmediately over the lower $\mathrm{end}$ of the tib a, ant about a couple of inches or so above the ankle-joint. From the lower end of this wound the tibirlis antirus muscle pr truded almost in its entirety, the belly of the muece lyins on the dorsum of the foot. The hæmorrange had evilently been very profuse, but had ceased when I saw the patient Fortunatrly no large vessel had been injured, s", hainis - atisfied myseli on this point, I divide 1 the tendon if the thlial's anticus at the lower end of the wound, and removed the muscle. I then cleansed the wound thoroughly with carbulised water, washing awav all dirt \&c., of whi b there was a comsiderab'e amount. Up in trying to anproximate the edges of the wound, I found, as I anticipated that sucl cou'd not be done, chiefly owing to loss of substance. t'verefore applied a pad of lint soaked in carholic oil, an bandnged tre limb, tnjoining perfect rest. After this punt the history is simply that of a granulating sore; threfere I will not occupy space in giving details. The diessmes were removed every alternate day. Everything went on 